\title{
Motion Reduction for C-Arm Computed Tomography of the Pulmonary Arteries: Image Quality of a Motion Correction Algorithm in Patients with Chronic Thromboembolic Hypertension During Balloon Pulmonary Angioplasty \\ Verbesserung der Bildqualität selektiver C-Arm- Computertomografien im Rahmen der pulmonalen Ballonangioplastie bei Patienten mit chronischer thromboembolischer pulmonaler Hypertonie: Anwendbarkeit und potenzieller klinischer Nutzen
}

\section{Authors}

Sabine Maschke', Thomas Werncke', Lena Sophie Becker ${ }^{1}$, Julius Renne ${ }^{1}$, Cornelia Lieselotte Angelika Dewald ${ }^{1}$, Karen M. Olsson ${ }^{2}$, Marius M. Hoeper ${ }^{2}$, Frank K. Wacker ${ }^{1}$, Bernhard C. Meyer ${ }^{1}$, Jan B. Hinrichs ${ }^{1}$

\author{
Affiliations \\ 1 Department of Diagnostic and Interventional Radiology, \\ $\mathrm{MHH}$, Hannover, Germany \\ 2 Clinic for Pneumology, MHH, Hannover, Germany
}

Key words

angioplasty, pulmonary angiography, pulmonary

hypertension, cone beam computed tomography

received 20.10.2020

accepted 07.01.2021

published online 25.02 .2021

Bibliography

Fortschr Röntgenstr 2021; 193: 1074-1080

DOI 10.1055/a-1354-6736

ISSN 1438-9029

(c) 2021. Thieme. All rights reserved.

Georg Thieme Verlag KG, Rüdigerstraße 14,

70469 Stuttgart, Germany

Correspondence

Prof. Jan B. Hinrichs

Diagnostische und Interventionelle Radiologie, $\mathrm{MHH}$,

Carl-Neuberg-Straße 1, 30625 Hannover, Germany

Tel.: +49/511/5323421

Fax: $+49 / 511 / 5329421$

hinrichs.jan@mh-hannover.de

\section{ZUSAMMENFASSUNG}

Ziel Evaluation des potenziellen Nutzens eines automatisierten Bewegungskorrekturalgorithmus hinsichtlich der Verbesserung der Bildqualität der selektiven C-Arm-Computertomografie (CACT) der Pulmonalarterien im Rahmen der pulmonalen Ballonangioplastie (BPA) bei Patienten mit chronischer thromboembolischer pulmonaler Hypertonie (CTEPH).
Material und Methoden Dreißig Rohdatensätze von selektiven CACT, die im Rahmen von BPA-Prozeduren akquiriert wurden, wurden mittels Standard- (CACTorg) oder Bewegungskorrekturalgorithmus (CACTmc) unter der Verwendung von 400 Iterationen rekonstruiert. Zwei Leser bewerteten unabhängig die Bildqualität für Segmentarterien und subsegmentale Äste anhand 5 definierter Kriterien: Schärfe des Gefäßes, Bewegungsartefakte, Abgrenzbarkeit der Bronchien, Gefäßgeometrie und Erkennbarkeit potenziell mittels BPA therapierbarer Befunde. Alle evaluierten Bildqualitätskriterien wurden von Grad 1 bis Grad 3 bewertet: Grad 1: exzellente Qualität, Grad 2: gute Qualität, Grad 3: schlechte/deutlich beeinträchtigte Qualität. Übereinstimmungen zwischen den Untersuchern wurden mittels Cohens Kappa ermittelt. Aufgrund exzellenter Übereinstimmung wurden die Ergebnisse beider Leser zusammengefasst und in der Folge als ein Datensatz verwendet. Unterschiede in der Bildqualität bezüglich der erhobenen Kriterien zwischen dem originalen und dem bearbeiteten Datensatz wurden für alle beurteilten PAS und ihre nächst untergeordneten Äste unter Verwendung des geparten Wilcoxon-Vorzeichen-Rang-Tests erhoben.

Ergebnisse Die Interobserver-Übereinstimmung war exzellent für alle untersuchten Kriterien der Bildqualität $(\kappa>0,81)$. Bezogen auf den gesamten Gefäßbaum konnte hinsichtlich aller evaluierten Kriterien eine signifikante Verbesserung der Bildqualität für CACTmc im Vergleich zur ohnehin schon guten Bildqualität für CACTorg beobachtet werden $(p<0,01)$. Bei separater Betrachtung der segmentalen und subsegmentalen Gefäßabschnitte konnte eine signifikante Verbesserung aller Bildqualitätskritierien für CACTmc beobachtet werden $(p<0,01)$. Während die Bewertungen für CACTmc in beiden Gefäßabschnitten (segmental and subsegmental) für alle beurteilten Kriterien konstant blieben, waren die für CACTorg in den subsegmentalen Ästen etwas schlechter. 
Schlussfolgerung Die Anwendung eines Bewegungskorrekturalgorithmus auf selektive CACT der Pulmonalarterien ist möglich und kann die Bildqualität signifikant verbessern.

\section{Kernaussagen:}

- Die Aussagekraft der CACT kann entscheidend durch nicht immer vermeidbare Bewegungsartefakte gemindert werden.

- Mittels Bewegungskorrekturalgorithmus kann die Bildqualität selektiver CACT der Pulmonalarterien signifikant verbessert werden.

- Besonders subsegmentale Äste kommen besser zur Darstellung.

\section{ABSTRACT}

Purpose To evaluate the feasibility and image quality of a motion correction algorithm for supra-selective C-arm computed tomography (CACT) of the pulmonary arteries in patients with chronic thromboembolic pulmonary hypertension (CTEPH) undergoing balloon pulmonary angioplasty (BPA).

Materials \& Methods CACT raw data acquired during 30 consecutive BPAs were used for image reconstruction using either standard (CACTorg) or a motion correction algorithm (CACTmc), using 400 iterations. Two readers independently evaluated 188 segmental and 564 sub-segmental contrastenhanced pulmonary arteries in each reconstruction. The following categories were assessed: Sharpness of the vessel, motion artifacts, delineation of bronchial structures, vessel geometry, and visibility of treatable lesions. The mentioned criteria were rated from grade 1 to grade 3: grade 1: excellent quality; grade 2: good quality; grade 3: poor/seriously impaired quality. Inter-observer agreement was calculated using Cohen's Kappa. Due to an excellent agreement, the ratings of both readers were merged. Differences in the assessed image quality criteria were evaluated using pairwise Wilcoxon signed-rank test.

Results Inter-observer agreement was excellent for all evaluated image quality criteria $(\kappa>0.81)$. For all assessed image quality criteria, the ratings on CACTorg were good but improved significantly for CACTmc to excellent for the whole vascular tree $(p<0.01)$. When considering segmental and sub-segmental levels individually, all image quality criteria improved significantly for CACTmc on both levels $(p<0.01)$. While ratings of CACTmc were constant for both levels (segmental and sub-segmental) for all criteria, the ratings of CACTorg were slightly impaired for the sub-segmental arteries.

Conclusion Motion correction for supra-selective contrastenhanced CACT of the pulmonary arteries is feasible and improves the overall image quality.

\section{Key Points:}

- Motion artifacts can severely impair the diagnostic accuracy of CACT.

- A motion correction algorithm can significantly improve image quality in CACT of the pulmonary arteries.

- Especially the overall image quality of sub-segmental branches is significantly improved.

\section{Citation Format}

- Maschke S, Werncke T, Becker LS et al. Motion Reduction for C-Arm Computed Tomography of the Pulmonary Arteries: Image Quality of a Motion Correction Algorithm in Patients with Chronic Thromboembolic Hypertension During Balloon Pulmonary Angioplasty. Fortschr Röntgenstr 2021; 193: 1074-1080

\section{Introduction}

C-arm computed tomography (CACT) has become an established tool for both diagnostic workup and peri-procedural guidance of manifold angiographic procedures [1-7]. Various studies have reported advantages of CACT compared with projection-based imaging (2 D digital subtraction angiography (DSA)) [1-7]. Early reports summarized that CACT has the potential to expedite interventional procedures that require three-dimensional information and navigation [7, 8]. This is especially true for complex procedures such as balloon pulmonary angioplasty (BPA) in patients with chronic thromboembolic pulmonary hypertension (CTEPH) where CACT guidance gains increasing importance [3, 9]. BPA is a treatment option for inoperable CTEPH patients and addresses peripheral web-like stenoses and intraluminal bands as well as total occlusions in segmental and sub-segmental pulmonary arteries as low as $1 \mathrm{~mm}$ in diameter. Here, CACT serves as a diagnostic tool to provide accurate diagnosis and precise evaluation of suitable lesions for BPA. Moreover, CACT enables the identification of lesions in a complex 3-dimensional vasculature, facilitating the potentially challenging passing of target lesions safely, thus minimizing the risk for potentially life-threatening complications [1, 9]. Hence, BPA benefits from optimal procedure guidance and the clear identification of small intravascular targets [9-11]. However, the image quality of CACT can be somewhat limited by motion artifacts, especially in patients with shortness of breath $[4,12]$. This results in blurring and streaking artifacts that can cause the loss of critical peri-procedural information, especially in smaller, sub-segmental vessels that might be even more affected by motion artifacts but are the typical location for lesions characteristic of CTEPH.

In order to improve motion artifacts in 3D datasets, an image reconstruction algorithm (Vascular Reconstruction algorithm (CAVAREC) Siemens Healthineers, Germany) was developed. It is based on an algorithm previously used for cardiac imaging studies and was further modified for non-cardiac CACT [13-15]. The purpose of our study was to evaluate the modified motion correction algorithm regarding image quality in selective CACT of the pulmonary arteries in patients with chronic thromboembolic hypertension undergoing balloon pulmonary angioplasty. 


\section{Materials and Methods}

Our local ethics committee approved this retrospective study and waived consent. In our institution, patients with suspected CTEPH undergo a standardized diagnostic workup according to current guidelines $[11,16]$. Treatment for each patient is based on an interdisciplinary CTEPH board decision. During the study period from May 2019 to January 2020, a total of 17 consecutive patients (10 male, 7 female; mean age $65.3 \pm 16.7$ years; mean pulmonary arterial pressure (mPAP) $38.8 \pm 16.0 \mathrm{mmHg}$ ) were scheduled for $\mathrm{BPA}$ resulting in 30 procedures with contrast-enhanced supra-selective CACT acquisitions of the right lung ( $n=16$; 1 apical trunk, 1 interlobar trunk, 6 basal trunk, 5 interlobar and basal trunk, 3 whole right lung) or left lung ( $n=14 ; 1$ main artery, 1 interlobar trunk, 5 basal trunk, 3 interlobar and basal trunk, 1 main artery and interlobar trunk, 3 whole left lung). Written informed consent concerning the intervention and the concomitant diagnostic imaging was obtained from all patients. The acquired raw data was used for this retrospective study.

\section{Image Acquisition}

All procedures were performed on a monoplane, ceiling-mounted angiographic system (Artis Q, Siemens Healthineers, Forchheim, Germany) or on a monoplane, robotic-arm-mounted angiographic system (ARTIS pheno, Siemens Healthineers, Forchheim, Germany). Through femoral access, a long 6F sheath (Destination peripheral guiding sheath, Terumo Europe, Leuven, Belgium) combined with a diagnostic catheter was placed in the pulmonary artery of interest. A contrast-enhanced CACT scan of the pulmonary arteries either of the right or the left lung with selective catheter positions as described above was acquired within a modest inspiratory breath-hold using a dual-barrel injector (Accutron HP-D, Medtron AG, Saarbrücken, Germany; total injected volume $50 \mathrm{~mL}$, comprising $35 \mathrm{~mL}$ of lomeprol $300 \mathrm{mg} \mathrm{I} / \mathrm{ml}$ mixed with $15 \mathrm{ml}$ of normal saline; flow rate $6 \mathrm{ml} / \mathrm{s}$,) applying the manufacturer's preset (Artis Q: 6 sec DR DynaCT preset, Siemens Healthineers; ARTIS pheno: 5 sec DR DynaCT preset, Siemens Healthineers). The original CACT dataset with an isotropic voxel size of $(0.4 \mathrm{~mm})^{3}$ was computed on a dedicated workstation (syngo $\mathrm{X}$ workplace VD20C, Siemens Healthineers).

\section{Image Post-Processing}

The 3D image reconstruction prototype software was applied to the original raw dataset. The software estimates motion in the acquired images and compensates for it in the reconstruction step. Motion estimation and compensation are limited to sparse, high-contrast objects. At first, using the raw CACT dataset, a 3D reconstruction was generated showing automatically segmented high-contrast objects only. Afterwards, volume punching for stationary high-contrast objects (like bones or extraneous material) was applied manually as described previously [1,3]. This step is crucial, as stationary bones might interfere with the algorithm, potentially falsifying the effect of motion correction on the pulmonary arteries. Experienced users perform manual volume punching within 1-2 minutes. With usage of iterative motion es- timation and compensation of a 4 D deformable motion vector field, intermediate $3 \mathrm{D}$ images register well to the $3 \mathrm{D}$ reference image. This 3D reference image is intermittently updated using high-contrast segmentation of the latest intermediate 3D image. The method uses all projection images and does not require any periodicity in the motion. The whole reconstruction procedure takes about five minutes. For motion correction of selective CACT images of the pulmonary arteries, we used 400 iterations in total and an iteration update/display every 100 iterations. The step size was $2 \mathrm{~mm}$ and motion resolution $25 \mathrm{~mm}$.

\section{Image Analysis}

Two blinded readers with 4 and 8 years (R1: blinded for anonymity; R2: blinded for anonymity) of clinical experience in cardiovascular and interventional imaging independently reviewed anonymized images of the original CACT acquisition ( $\left.C A C T_{\text {org }}\right)$ and the motion-corrected CACT acquisition (CACT $\mathrm{mc}_{\mathrm{c}}$ ) in random order. On a 3D PACS workstation (Visage 7.1.14, Visage Imaging, Berlin, Germany) average intensity projections (AvIP), maximum intensity projections (MIP) with variable slab thickness for optimal image interpretation, and thin-slice multiplanar reformats (MPR) in axial coronal, sagittal, or oblique orientation were used for image assessment.

Image quality was assessed on a segmental and sub-segmental basis according to the adjusted Boyden nomenclature [17]. Segmental pulmonary arteries (SPA) 1 and 2 as well as 7 and 8 on the left side were assessed as two segments due to possible separate treatment of these arteries during BPA. In addition to the SPA, the next subordinated sub-segmental pulmonary arteries (SSPA) were also evaluated. Image quality was assessed for all pulmonary arterial segments (PAS: SPA and SSPA) regarding the following image quality criteria (IQC): a) sharpness of the vessel, i. e., delineation of the vascular margins from the surrounding lung parenchyma; b) motion artifacts, i. e., degree of streaking and blurring next to the vessel; c) delineation of bronchial structures, i. e., clear delineation of the bronchial wall; d) vessel geometry, i. e., visibility of the origin and course; e) visibility of treatable lesions. All mentioned criteria were rated from grade 1 to grade 3 : grade 1: excellent quality; grade 2: good quality; grade 3: poor/seriously impaired quality.

\section{Statistical Analysis}

Descriptive statistical analyses of the patient demographics were calculated (mean value \pm standard deviation). The inter-observer agreement of the IQC rating for all PAS on the $\mathrm{CACT}_{\text {org }}$ and $\mathrm{CACT}_{\mathrm{mc}}$ images was assessed using Cohen's kappa ( $\mathrm{k}$ ). As the inter-observer agreement was excellent, the IQC ratings of both readers were merged for further evaluation of IQC rating in $\mathrm{CACT}_{\text {org }}$ and $\mathrm{CACT}_{\mathrm{mc}}[18,19]$. The mean IQC rating with standard deviation was calculated. Potential differences between IQC rating for $C_{\text {org }}$ and $C_{\text {oCT }}$ mc were analyzed for all SPA and SSPA using the pairwise Wilcoxon signed-rank test. A p-value of $<0.05$ was defined as statistically significant. Statistical analysis was conducted with R (version 3.6.1, http://www.r-project.org with package "IRR" version 0.84.1). 
- Table 1 Inter-observer agreement for assessed image quality criteria.

- Tab. 1 Interobserver-Übereinstimmung für die bewerteten Kriterien der Bildqualität.

\begin{tabular}{|l|l|}
\hline CACT $_{\text {org }}$ & \\
\hline IQC & kappa-value $(\mathrm{k})$ \\
\hline Sharpness of the vessel & 0.86 \\
\hline Motion artifacts & 0.84 \\
\hline Sharpness of bronchial structures & 0.88 \\
\hline Vessel geometry & 0.88 \\
\hline Visibility of treatable lesion & 0.83 \\
\hline CACTmc & \\
\hline IQC & kappa-value (к) \\
\hline Sharpness of the vessel & 0.91 \\
\hline Motion artifacts & 0.84 \\
\hline Sharpness of bronchial structures & 0.88 \\
\hline Vessel geometry & 0.90 \\
\hline Visibility of treatable lesions & 0.93 \\
\hline
\end{tabular}

\section{Results}

We included 30 supra-selective CACT scans in this analysis. Overall, 188 segmental pulmonary arteries (SPA) and 564 sub-segmental pulmonary arteries (SSPA) were analyzed during BPA with selective CACT and were, therefore, evaluated in our study. The inter-observer agreement for all IQC of the $C A C T_{\text {org }}$ and $C A C T_{m c}$ images was excellent (see $>$ Table 1 ). Thus, the IQC rating of both readers was merged and used to calculate and compare the mean IQC rating for the $\mathrm{CACT}_{\text {org }}$ and $\mathrm{CACT}_{\mathrm{mc}}$ images, respectively. The mean IQC rating for all PAS on the $C A C T_{\text {org }}$ image was good regarding all evaluated quality criteria ( $\triangleright$ Table 2 ). However, the IQC rating for $C A C T_{m c}$ images was significantly better in all categories $(p<0.0001)$ (see $>$ Table 2, > Fig. 1). For instance, the delineation of bronchial structures, a parameter most frequently affected by motion artifacts $\left(\mathrm{CACT}_{\text {org }}\right.$ vs. $\mathrm{CACT}_{\mathrm{mc}}: 1.77 \pm 0.77$ vs. $1.32 \pm 0.48 ; p<0.01)$, improved significantly following motion correction.

Furthermore, we evaluated the impact of the motion correction algorithm on both segmental and sub-segmental arteries to determine potential differences regarding the depiction of more central and more peripheral structures. The IQC rating was good for $C_{\text {OC }}$ org $S P A$ and SSPA. Nonetheless, the IQC rating for $C A C T_{\text {org }}$ images tended to be slightly worse when comparing SSPA to SPA. For example, the mean visibility of treatable lesions on $\mathrm{CACT}_{\text {org }}$ images was rated $1.52 \pm 0.64$ for SPA and $1.62 \pm 0.67$ for SSPA, whereas on $\mathrm{CACT}_{\mathrm{mc}}$ images the rating was equal for SPA (1.18 \pm $0.39)$ and SSPA (1.17 \pm 0.38 ; see - Table 3; - Fig. 2).
- Table 2 Image quality category rating on $\mathrm{CACT}_{\text {org }}$ and $\mathrm{CACT}_{\mathrm{mc}}$ images.

- Tab. 2 Bewertung der Kriterien der Bildqualität in CACT $_{\text {org }}$ und $\mathrm{CACT}_{\mathrm{mc}}$.

\begin{tabular}{|l|l|l|l|}
\hline IQC* & $\begin{array}{l}\text { Rating } \\
\text { on CACT }\end{array}$ & $\begin{array}{l}\text { Rating } \\
\text { on } \text { CACT }_{\mathbf{m c}}\end{array}$ & p-value \\
\hline $\begin{array}{l}\text { Sharpness of the } \\
\text { vessel }\end{array}$ & $1.61 \pm 0.69$ & $1.18 \pm 0.38$ & $<0.01$ \\
\hline Motion artifacts & $1.64 \pm 0.71$ & $1.19 \pm 0.40$ & $<0.01$ \\
\hline $\begin{array}{l}\text { Delineation of } \\
\text { bronchial structures }\end{array}$ & $1.77 \pm 0.77$ & $1.32 \pm 0.48$ & $<0.01$ \\
\hline Vessel geometry & $1.64 \pm 0.72$ & $1.18 \pm 0.38$ & $<0.01$ \\
\hline Visibility of treatable & $1.59 \pm 0.66$ & $1.17 \pm 0.38$ & $<0.01$ \\
\hline lesions & & & \\
\hline
\end{tabular}

All evaluated IQC (imaging quality criteria) were rated from grade 1 to grade 3: grade 1: excellent quality; grade 2: good quality; grade 3: poor/seriously impaired quality. Values are given as mean \pm standard deviation.

Alle evaluierten IQC (Bildqualitätskriterien) wurden von Grad 1 bis Grad 3 bewertet: Grad 1: exzellente Qualität, Grad 2: gute Qualität, Grad 3: schlechte/deutlich beeinträchtigte Qualität. Die Werte sind als Mittelwert \pm Standardabweichung angegeben.

\section{Discussion}

Applying dedicated motion correction software to selective contrast-enhanced CACT imaging of the pulmonary arteries significantly increases the image quality of pulmonary arteries possibly leading to a more precise depiction of CTEPH findings.

The value and advantages of CACT regarding improvement of the diagnostic workup and peri-interventional guidance have been reported for multiple organs and procedures [1-7]. For CTEPH patients, CACT provides additional information to conventional DSA by visualizing distal lesions not assessable by surgical pulmonary endarterectomy (PEA). This is important for BPA, an interventional procedure that targets webs, bands, and stenosis in distal areas of the pulmonary vasculature $[10,20]$. Several studies on CTEPH patients reported that a detailed depiction of the pulmonary vascular tree helps to evaluate suitable treatment options and to optimize peri-interventional guidance since successful BPA depends on the clear depiction of target lesions in sub-segmental pulmonary arteries [1, 3, 9]. However, up to $7 \%$ of CACT scans acquired during diagnostic workup of patients with CTEPH show impaired image quality mainly due to severe motion artifacts, emphasizing the importance of a comprehensive motion correction algorithm to obtain high-quality diagnostic CACT images and to gain sufficient and valuable information as well as to avoid repeated image acquisitions $[4,5]$.

In our study, the image quality of selective $\mathrm{CACT}_{\text {org }}$ images was rated good for all assessed criteria, indicating a high-quality level of the acquired CACT images. Nevertheless, the motion correc- 


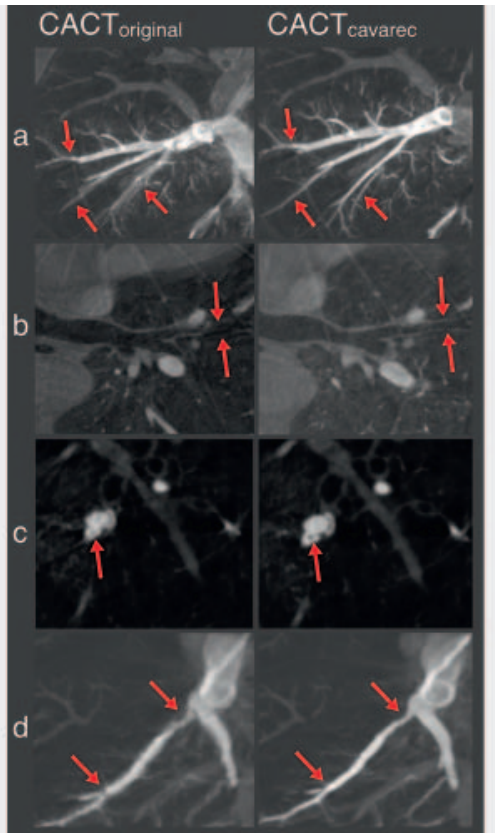

- Fig. 1 Examples of CACTorg and CACTmc for assessed image quality criteria. a Sharpness of the vessel: $10 \mathrm{~mm}$ sagittal MIP of CACTorg shows blurred vascular walls and the course of the right segment 5 arteries is not clearly displayed (red arrows). Corresponding CACTmc shows clearly defined vascular margins (red arrows). b Delineation of bronchial structures: oblique MPR of CACTorg shows significant blurring of the bronchial wall (left lower lobe), in particular on sub-segmental levels (red arrows). Corresponding CACTmc depicts the whole bronchial tree far into the periphery (red arrows). c Visibility of treatable lesions: axial MPR of CACTorg shows blurred luminal view of the left segment 10 artery without a clear depiction of the lesions (red arrow). Corresponding CACTmc uncovers typical intra-luminal bands, treatable by BPA (red arrow). $\mathbf{d}$ Vessel geometry: coronal $10 \mathrm{~mm}$ MIP of CACTorg displays a blurred origin and course of the right segment 8 artery without a clear depiction of the lumen. Origin of the vessel and originating branches are hard to identify (red arrows). Corresponding CACTmc shows a clear depiction of the course of the vessel from the origin to the periphery with sharp vascular margins (red arrows).

- Abb. 1 Beispiele von CACTorg und CACTmc für unterschiedliche Kriterien der Bildqualität. a Schärfe des Gefäßes: $\mathrm{n}$ der sagittalen $10 \mathrm{~mm}-M I P$ zeigt sich in der CACTorg eine deutliche Unschärfe der Gefäßwände. Zudem ist der Verlauf der rechtsseitigen Segment-5-Arterie nicht deutlich zu erkennen (rote Pfeile). In der korrespondierenden CACTmc sind die Gefäßränder deutlich und klar abgrenzbar. b Abgrenzbarkeit der Bronchien: Die koronare 10mm-MIP zeigt in der CACTorg eine signifikante Unschärfe der Bronchialwände im linken Unterlappen, im Besonderen im subsegmentalen Level (rote Pfeile). In der korrespondieren CACTmc lässt sich der gesamte Bronchialbaum bis weit in die Peripherie deutlich abgrenzen. c Sichtbarkeit behandelbarer Befunde: Die axiale MPR der CACTorg zeigt einen unscharfen, verschwommenen Gefäßquerschnitt der linken Segment-10-Arterie ohne eindeutig erkennbaren Befund (roter Pfeil). Die korrespondierende CACTmc offenbart ein für die CTEPH typisches intraluminales Band, welches sich gut mittels BPA behandeln lässt (roter Pfeil). $\mathbf{d}$ Gefäßgeometrie: Die koronare 10mm-MIP der CACTorg zeigt nur unscharf Ursprung und Verlauf der rechten Segment-8-Arterie ohne deutliche Erkennbarkeit des Gefäßlumens. Der Ursprung des Gefäßes und die abgehenden Äste sind schwer zu identifizieren (rote Pfeile). In der korrespondierenden CACTmc ist der Verlauf des Gefäßes von seinem Ursprung bis in die Peripherie deutlich erkennbar mit scharf abgrenzbaren Gefäßrändern (rote Pfeile).

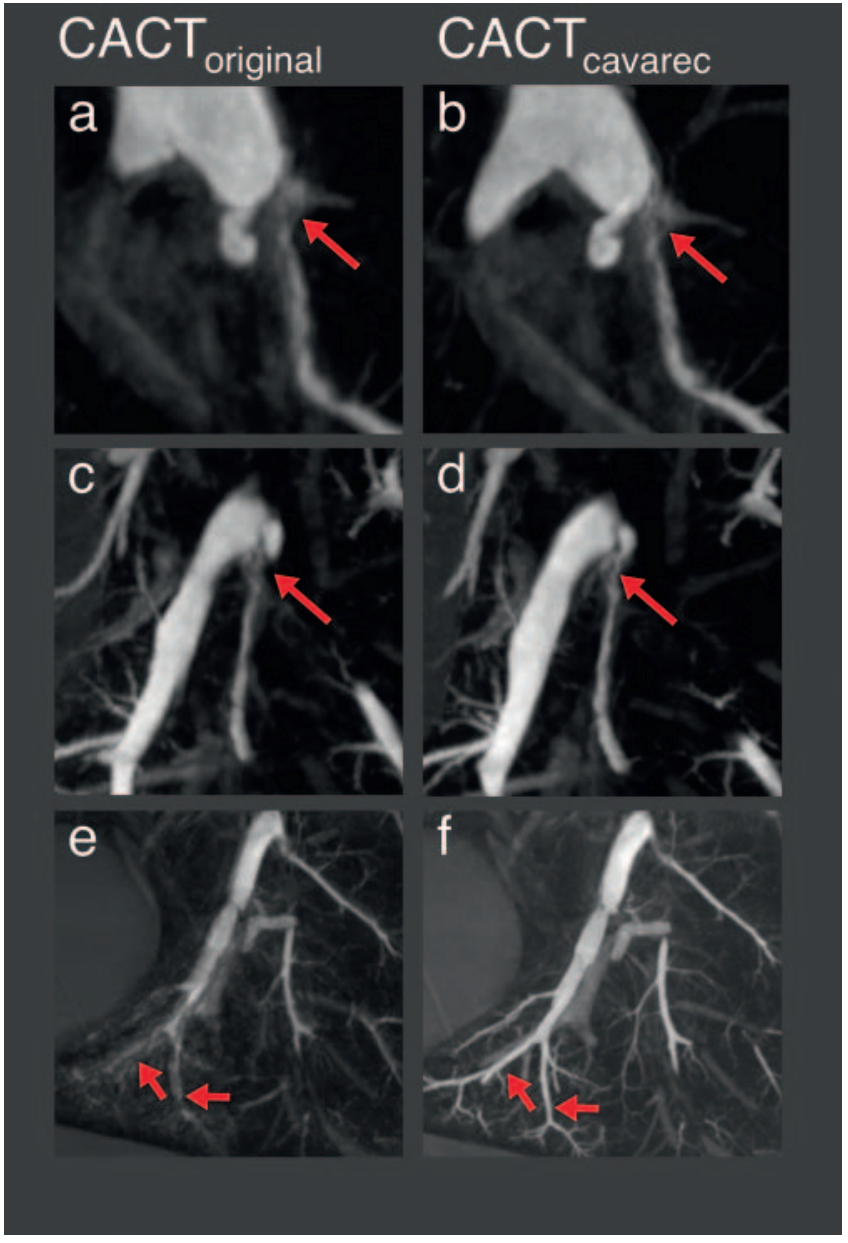

- Fig. 2 Detailed examples of CACTorg and CACTmc showing improvement of the depiction of treatable lesions and vessel geometry. a-d sagittal, $10 \mathrm{~mm}$ a, b and coronal, $20 \mathrm{~mm} \mathbf{c}, \mathbf{d}$ MIP of the same patient. CACTorg a, $\mathbf{c}$ shows blurred pulmonary vascular branch of the left segment 10 artery without clear depiction of the origin and questionable intravascular bands. The corresponding CACTmc $\mathbf{b}, \mathbf{d}$ reveals the origin and course of the vessel more clearly and an intravascular band close to the bifurcation is shown. e Sagittal, $10 \mathrm{~mm}$ MIP of CACTorg shows significant blurring of the left segment 7 artery due to cardiac motion and missing traceability of the peripheral branches. Corresponding CACTmc $\mathbf{f}$ shows a precise depiction of the whole vascular tree. Vascular course, originating branches, and potentially treatable lesions can be assessed in detail.

- Abb. 2 Detaillierte Beispiele für die verbesserte Erkennbarkeit behandelbarer Läsionen und Gefäßgeometrie in der CACTmc im Vergleich zur CACTorg. a-f Sagittale, $10 \mathrm{~mm}$ - a, b und koronare, 20 mm c, d -MIP des gleichen Patienten. Die CACTorg a, c zeigt eine deutliche Unschärfe des abgebildeten Gefäßastes der linken Segment-10-Arterie ohne eindeutig erkennbaren Gefäßursprung und fraglichen intravaskulären Bändern. In der korrespondieren CACTmc b, $\mathbf{d}$ sind Ursprung und Verlauf des Gefäßes klar erkennbar, ebenso wie ein unmittelbar an der Gefäßbifurkation gelegenes intravaskuläres Band. e In der sagittalen, 10 mm-MIP der CACTorg ist die linke Segment-7-Arterie aufgrund kardialer Bewegungen deutlich unscharf und verschwommen abgebildet. Die peripheren Äste lassen sich nicht sicher nachverfolgen. In der korrespondierenden CACTmc $\mathbf{f}$ ist der gesamte Gefäßbaum deutlich erkennbar. Der Gefäßverlauf, die abgehenden Äste und potenziell behandelbare Gefäßbefunde können detailliert nachvollzogen werden. 
- Table 3 Differences in image quality between segmental and sub-segmental branches on CACT $_{\text {org }}$ and CACT $_{\text {mc }}$ images.

- Tab.3 Unterschiede in der Bildqualität zwischen segmentalen und subsegmentalen Ästen in $\mathrm{CACT}_{\text {org }}$ und $\mathrm{CACT}_{\mathrm{mc}}$.

\begin{tabular}{|c|c|c|c|c|c|c|}
\hline \multirow[b]{2}{*}{ IQC** } & \multicolumn{2}{|l|}{ SPA* } & \multirow[b]{2}{*}{$\mathrm{p}$-value } & \multicolumn{2}{|l|}{ SSPA* } & \multirow[b]{2}{*}{ p-value } \\
\hline & $\begin{array}{l}\text { Rating } \\
\text { on } \mathrm{CACT}_{\text {org }}\end{array}$ & $\begin{array}{l}\text { Rating } \\
\text { on } \mathrm{CACT}_{\mathrm{mc}}\end{array}$ & & $\begin{array}{l}\text { Rating } \\
{\text { on } \mathrm{CACT}_{\text {org }}}\end{array}$ & $\begin{array}{l}\text { Rating } \\
\text { on } \mathrm{CACT}_{\mathrm{mc}}\end{array}$ & \\
\hline Sharpness of the vessel & $1.51 \pm 0.66$ & $1.19 \pm 0.40$ & $<0.01$ & $1.63 \pm 0.70$ & $1.18 \pm 0.38$ & $<0.01$ \\
\hline Motion artifacts & $1.55 \pm 0.69$ & $1.20 \pm 0.40$ & $<0.01$ & $1.67 \pm 0.72$ & $1.19 \pm 0.39$ & $<0.01$ \\
\hline $\begin{array}{l}\text { Delineation of bronchial } \\
\text { structures }\end{array}$ & $1.68 \pm 0.77$ & $1.31 \pm 0.47$ & $<0.01$ & $1.80 \pm 0.77$ & $1.32 \pm 0.48$ & $<0.01$ \\
\hline Vessel geometry & $1.53 \pm 0.67$ & $1.18 \pm 0.38$ & $<0.01$ & $1.68 \pm 0.73$ & $1.18 \pm 0.38$ & $<0.01$ \\
\hline Visibility of treatable lesions & $1.52 \pm 0.64$ & $1.18 \pm 0.39$ & $<0.01$ & $1.62 \pm 0.67$ & $1.17 \pm 0.38$ & $<0.01$ \\
\hline $\begin{array}{l}\text { * SPA = segmental pulmonar } \\
\text { SPA = segmentale Pulmona } \\
\text { All evaluated IQC (imaging } \\
\text { impaired quality. Values ar } \\
\text { Alle evaluierten IQC (Bildqu } \\
\text { deutlich beeinträchtigte Q }\end{array}$ & $\begin{array}{l}\text { y; SSPA = sub- } \\
\text {; SSPA = subs } \\
\text { y criteria) wer } \\
\text { as mean } \pm \text { st } \\
\text { kriterien) wur } \\
\text { Die Werte sin }\end{array}$ & $\begin{array}{l}\text { al pulmonarry } \\
\text { le Pulmonalar } \\
\text { om grade } 1 \text { to } \\
\text { eviation. } \\
\text { irad } 1 \text { bis Grac } \\
\text { telwert } \pm \text { Stan }\end{array}$ & $\begin{array}{l}\text { grade 1: ex } \\
\text { tet: Grad } 1 \\
\text { eichung an }\end{array}$ & $\begin{array}{l}\text { thuality; gra } \\
\text { llente Qualitä } \\
\text { en. }\end{array}$ & d quality; gra & $\begin{array}{l}\text { r/seriously } \\
\text { schlechte/ }\end{array}$ \\
\hline
\end{tabular}

tion algorithm significantly improved the image quality. Most notably, the sub-segmental pulmonary arteries as potential targets of BPA benefitted most with image quality comparably high in both SPA and SSPA. In contrast, the image quality decreased from SPA to SSPA in the original CACT datasets. As a detailed depiction of more peripheral pulmonary arteries is crucial for diagnosis and therapy planning in patients with $C T E P H$, our results underline the importance of image optimization by applying a motion correction algorithm.

The evaluated categories (sharpness of vessel, motion artifacts, and delineation of bronchial structures) are helpful to evaluate general image quality. The grade of motion artifacts as indicated by streaking and blurring around the vessels reflects the extent of potential disruptive factors compromising the diagnostic value of the examination. The clear identification of the vascular margins may optimize the measurements of the actual vessel size. As the balloon size used for BPA can be adjusted to the vessel diameter based on CACT, this image quality criteria may indirectly affect the success and safety of BPA [1, 3, 9]. A precise delineation of bronchial structures is helpful for the detection of completely occluded pulmonary arteries, as these typically run parallel to each other. Therefore, enhanced depiction of the bronchi in the periphery of the lung may have a substantial impact on BPA guidance. The categories vessel geometry and visibility of treatable lesions are matters of special importance, directly influencing therapeutic decision-making. Vessel geometry, defined by clear visibility of the origin and course of the pulmonary artery of interest and its branches, is crucial to avoid perforations of the arteries with the guidewire, while probing the target lesion for BPA. Furthermore, the visibility of treatable lesions is a basic requirement to plan and perform interventional therapy [9, 21-23].

Different attempts to reduce CACT motion artifacts are reported in the literature [24-26]. Berger et al. introduced a theoretical concept using dedicated phantoms with artificially induced motion artifacts [24]. The method described by Klugmann et al. is time-consuming as it requires manual vessel segmentation of the whole vascular tree [25]. Riblett et al. reported on a promising semi-automated reconstruction algorithm, consisting of a combination of groupwise deformable image registration and motioncompensated image reconstruction algorithms [26]. Nevertheless, image reconstruction takes 6-10 hours [26]. In a more recent study, Dioguardi Burgio et al. reported evaluation of a motion correction algorithm with a remarkably short reconstruction time in a clinical cohort of patients undergoing liver directed therapies [27]. Overall, four readers evaluated different criteria in two groups (with and without breathing artifacts). Dioguardi Burgio et al. stated that image quality is enhanced in the breathing artifact group, while image quality is maintained in the no-breathing group [27]. The motion correction prototype algorithm used in our study generates the corrected dataset in about 5 minutes, which is an acceptable duration.

In addition to the reconstruction time, manual interaction is required. The algorithm uses objects of high density to compensate for motion artifacts. Thus, bones interfere with the depiction of structures of interest and need to be removed manually by volume punching of the dataset. This requires two to five minutes $[1,3,9]$. However, bone removal is also necessary to prepare the CACT dataset as an overlay for BPA guidance [3]. Still, an automated bone removal algorithm would be beneficial for both advanced motion correction and overlay preparation.

Our study was performed at a single institution. The motion correction algorithm prototype was applied retrospectively. Therefore, its true clinical impact on procedure planning and subsequent therapeutic outcome, can only be simulated. Moreover, there is no gold standard to evaluate CACT. Thus, the assessment criteria for the interpretation of image quality were determined 
by a consensus of experts before the study. The overall image quality of the CACT datasets included in this study was good, which proves the robustness of the technique. Therefore, the effect of the motion compensation algorithm on highly impaired datasets needs to be evaluated in a larger cohort.

In conclusion, motion correction for selective contrast-enhanced CACT of the pulmonary arteries is feasible and improves the overall image quality. Thus, it has the potential to improve not only diagnostic workup before the procedure but also guidance during BPA in patients with CTEPH.

\section{Conflict of Interest}

The authors declare that they have no conflict of interest.

\section{References}

[1] Maschke SK, Hinrichs JB, Renne J et al. C-Arm computed tomography (CACT)-guided balloon pulmonary angioplasty (BPA): Evaluation of patient safety and peri- and post-procedural complications. Eur Radiol 2019; 29: 1276-1284

[2] Angle JF. Cone-beam CT: vascular applications. Techniques in Vascular and Interventional Radiology 2013; 16: 144-149

[3] Hinrichs JB, Renne J, Hoeper MM et al. Balloon pulmonary angioplasty: applicability of C-Arm CT for procedure guidance. Eur Radiol 2016; 26: 4064-4071

[4] Hinrichs JB, Marquardt S, von Falck C et al. Comparison of C-arm Computed Tomography and Digital Subtraction Angiography in Patients with Chronic Thromboembolic Pulmonary Hypertension. Cardiovasc Intervent Radiol 2016; 39: 53-63

[5] Maschke SK, Werncke T, Becker LS et al. The Value of C-Arm Computed Tomography in Addition to Conventional Digital Subtraction Angiography in the Diagnostic Work-up of Patients with Suspected Chronic Thromboembolic Pulmonary Hypertension: An Update of 300 Patients. Acad Radiol 2020 Aug 4;S1076-6332(20)30421-9. doi:10.1016/ j.acra.2020.06.039. Online ahead of print

[6] Schott P, Katoh M, Fischer N et al. Radiation Dose in Prostatic Artery Embolization Using Cone-Beam CT and 3D Roadmap Software. J Vasc Interv Radiol 2019; 30: 1452-1458

[7] Tacher V, Radaelli A, Lin M et al. How I Do It: Cone-Beam CT during Transarterial Chemoembolization for Liver Cancer. Radiology 2015; 274 : 320-334. doi:10.1148/radiol.14131925

[8] Meyer BC, Frericks BB, Albrecht T et al. Contrast-Enhanced Abdominal Angiographic CT for Intra-abdominal Tumor Embolization: A New Tool for Vessel and Soft Tissue Visualization. Cardiovasc Intervent Radiol 2007; 30: 743-749

[9] Lin JL, Chen HM, Lin FC et al. Application of DynaCT angiographic reconstruction in balloon pulmonary angioplasty. Eur Radiol 2020; 30: 69506957. doi:10.1007/s00330-020-07028-9. Epub 2020 Jul 3

[10] Olsson KM, Wiedenroth CB, Kamp JC et al. Balloon pulmonary angioplasty for inoperable patients with chronic thromboembolic pulmonary hypertension: the initial German experience. European Respiratory Journal 2017; 49: 1602409

[11] Wilkens H, Konstantinides S, Lang I et al. [Chronic thromboembolic pulmonary hypertension: Recommendations of the Cologne Consensus Conference 2016]. Dtsch Med Wochenschr 2016; 141: S62-S69
[12] Rit S, Nijkamp J, van Herk M et al. Comparative study of respiratory motion correction techniques in cone-beam computed tomography. Radiother Oncol 2011; 100: 356-359

[13] Schultz C], Lauritsch G, Van Mieghem N et al. Rotational angiography with motion compensation: first-in-man use for the 3D evaluation of transcatheter valve prostheses. Eurolntervention 2015; 11: 442-449

[14] Rohkohl C, Lauritsch G, Biller L et al. ECG-gated interventional cardiac reconstruction for non-periodic motion. Med Image Comput Comput Assist Interv 2010; 13: 151-158

[15] Rohkohl C, Lauritsch G, Biller L et al. Interventional 4D motion estimation and reconstruction of cardiac vasculature without motion periodicity assumption. Medical Image Analysis 2010; 14: 687-694

[16] Galiè N, Humbert M, Vachiery JL et al. 2015 ESC/ERS Guidelines for the diagnosis and treatment of pulmonary hypertension: The Joint Task Force for the Diagnosis and Treatment of Pulmonary Hypertension of the European Society of Cardiology (ESC) and the European Respiratory Society (ERS): Endorsed by: Association for European Paediatric and Congenital Cardiology (AEPC), International Society for Heart and Lung Transplantation (ISHLT). Eur Heart J 2016; 37: 67-119

[17] BOYDEN EA. The Nomenclature of the Bronchopulmonary Segments and Their Blood Supply: (As Revised by the Seventh International Congress of Anatomists, 1960). Chest 1961; 39: 1-6

[18] Kundel HL, Polansky M. Measurement of Observer Agreement. Radiology 2003; 228: 303-308

[19] Werncke T, Hinrichs JB, Alikhani B et al. Virtual single source CT using dual source acquisition: Clinical applicability in run-off CT-angiography for intra-individual comparison of different scan protocols. Eur J Radiol 2018; 101: 149-156

[20] Feinstein JA, Goldhaber SZ, Lock JE et al. Balloon pulmonary angioplasty for treatment of chronic thromboembolic pulmonary hypertension. Circulation 2001; 103: 10-13

[21] Hinrichs JB, Werncke T, Kaireit T et al. C-Arm Computed Tomography Adds Diagnostic Information in Patients with Chronic Thromboembolic Pulmonary Hypertension and a Positive V/Q SPECT. Fortschr Röntgenstr 2017; 189: 49-56

[22] Sugiyama M, Fukuda T, Sanda Y et al. Organized thrombus in pulmonary arteries in patients with chronic thromboembolic pulmonary hypertension; imaging with cone beam computed tomography. Jpn J Radiol 2014; 32: 375-382. doi:10.1007/s11604-014-0319-8. Epub 2014 Apr 24

[23] Maschke SK, Renne J, Werncke T et al. Chronic thromboembolic pulmonary hypertension: Evaluation of 2D-perfusion angiography in patients who undergo balloon pulmonary angioplasty. Eur Radiol 2017; 27: 4264-4270

[24] Berger M, Xia Y, Aichinger W et al. Motion compensation for cone-beam CT using Fourier consistency conditions. Phys Med Biol 2017; 62: 71817215

[25] Klugmann A, Bier B, Müller K et al. Deformable respiratory motion correction for hepatic rotational angiography. Comput Med Imaging Graph 2018; 66: 82-89

[26] Riblett M], Christensen GE, Weiss E et al. Data-driven respiratory motion compensation for four-dimensional cone-beam computed tomography (4D-CBCT) using groupwise deformable registration. Medical Physics 2018; 45: 4471-4482

[27] Dioguardi Burgio M, Benseghir T, Roche V et al. Clinical impact of a new cone beam $\mathrm{CT}$ angiography respiratory motion artifact reduction algorithm during hepatic intra-arterial interventions. Eur Radiol 2020; 30: $163-174$ 